\title{
A Systematic Review and Meta-Analysis of the Risk of Microbial Contamination of Aseptically Prepared Doses in Different Environments
}

\author{
Peter Austin ${ }^{\mathrm{a}}$ and Marinos Elia ${ }^{\mathrm{b}}$

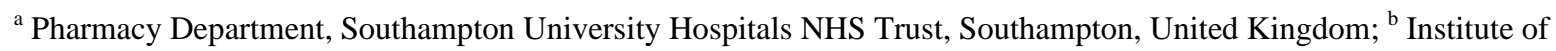 \\ Human Nutrition, University of Southampton, Southampton, United Kingdom.
}

Received, June 1, 2009, Revised, August 10, 2009, Accepted, August 24, 2009, Published, August 27, 2009.

\begin{abstract}
Purpose. To review microbial contamination rates about preparation of individual and batch doses using aseptic techniques within pharmaceutical (controlled) and clinical (ward and theatre) environments. Methods. Systematic review, involving amalgamation of data using a random effect model and metaanalysis. Results. A total of 19 studies from 17 reports (7277 doses), mostly single arm studies, were identified for analysis. The overall contamination rates for doses prepared in clinical environments were found to be $5.0 \%$ (95\% CI; $1.8 \%, 13.1 \%, \mathrm{n}=8$ studies) for individual doses and 2.0\% (95\% CI; $0.3 \%$, $13.1 \% ; \mathrm{n}=5$ ) for doses prepared as part of a batch. Rates for doses prepared in pharmaceutical environments were found to be $1.9 \%(95 \% \mathrm{CI} ; 0.8 \%, 4.2 \% ; \mathrm{n}=5)$ for individual doses and $0.0 \%(95 \% \mathrm{CI}$; $0.0 \%, 0.8 \% ; \mathrm{n}=1$ ) for doses prepared as part of a batch. The results indicate greater overall contamination rates of doses prepared in clinical than pharmaceutical environments, in those prepared individually than in batch preparation, and in those in which additions rather than no additions were made. Significant differences were only found between pharmaceutical and clinical environments for batch doses, and between batch and individual doses prepared in a pharmaceutical environment. The studies differed substantially in sample size, interventions and comparison conditions, especially in the clinical setting. The quality of the data was judged to be low. Conclusion. Contamination rates in clinical and pharmaceutical environments were commonly found to be unacceptably high. Intuitive recommendations for reducing contamination rates by carrying out the procedures in a pharmaceutical environment using batch doses are supported by an evidence base that needs to be strengthened further.
\end{abstract}

\section{INTRODUCTION}

The parenteral administration of contaminated doses can result in nosocomial bacteriaemia (1), significant morbidity (2) or death (3). Therefore, aseptic techniques are used to manipulate sterile starting components to prepare doses for parenteral administration in order to minimise microbiological contamination risk. However, aseptic techniques alone cannot guarantee that a sterile dose will ultimately be prepared because environmental contamination can occur during the manipulations. It is often argued that aseptically prepared doses for parenteral administration should be made in a dedicated pharmacy unit offering a controlled environment, where the risk of environmental contamination can be reduced to very low levels, rather than in a clinical environment, such as a hospital ward or operating theatre, where the risk of contamination is higher (4). To reduce the risk of microbial contamination a number of recommendations are made, including the following three. First, the British
Standard BS EN ISO 14644-1: 1999 (5) and the European Community Good Manufacturing Practice (EC GMP) require dedicated units to operate to defined high standards when using aseptic techniques to prepare doses $(6,7)$. Second, all aseptic dose preparation should be carried out in dedicated units with a minimum number of additions, according to the National UK guidelines (8-10). Third, any doses that are prepared in a clinical environment should be used immediately or appropriately destroyed (4). This last recommendation prevents batches from being prepared in clinical environments because whilst a batch generally involves fewer manipulations per final dose unit prepared, this could be offset by storage before use, which allows time for growth of any contaminating bacteria.

Corresponding Author: Peter Austin, Pharmacy Department, C level centre block, Southampton General Hospital, Tremona Road, Southampton, Hampshire, SO16 6YD, United Kingdom, Peter.Austin@suht.swest.nhs.uk 
For this reason only products prepared aseptically in a pharmaceutical environment may be stored before use, limiting the opportunity for batch preparation to dedicated pharmacy units.

These recommendations have a theoretical basis and an intuitive appeal, but surprisingly no synthesis of experimental information is available to support them. For example, if experimental evidence can be found to show that there is no difference in microbial contamination rates between doses prepared in dedicated units and clinical wards, then there may be reluctance to undertake time consuming and costly work in dedicated pharmaceutical units. Therefore, the aim of this study was to undertake a systematic review to examine the rates of microbiological contamination of doses prepared using 'aseptic' technique in different environments (see three hypotheses below) and to consider the current recommendations and to make a recommendation for future research in the light of the new information. A systematic review with meta-analysis would help resolve conflicting studies, increase power, improve the effect size estimate, and identify gaps in knowledge.

This review aimed to establish the reported prevalence of contamination rates of aseptically prepared doses. It also aimed to examine the simple overarching proposition that doses are more likely to be contaminated when prepared in environments with greater microbiological background contamination, stored for longer and manipulated more. Three specific component hypotheses were tested:

Hypothesis one: Doses are more likely to be contaminated if prepared in a clinical environment rather than in a pharmaceutical environment.

Hypothesis two: Doses are more likely to be contaminated if prepared individually rather than as part of a batch with the same environmental background.

Hypothesis three: Doses are more likely to be contaminated if additions are made rather than not made before administration in a clinical environment.

\section{METHODS}

The literature search was carried out using PubMed on 26 June 2007 for all available years (1950 onwards) using each of the following individual search terms, 'syringe', 'bag' and 'infusion', in combination with each of the following additional search terms, microbial, microbiological, bacteria, fungi, contaminated, contamination. Additional papers were sought through cross-referencing and discussions with experts in the field.

The combination of 'infusion' with 'bacteria' and 'infusion' with 'fungi' in the PubMed search identified 4878 and 2399 results respectively (total 7277). In an attempt to capture only those reporting doses that had been prepared from starting components these two word search terms were repeated using was an additional third term ('prepared', 'manufactured' or 'compounded'). This reduced the number of results from 7277 to 277 . All the other searches involved only two word combinations. The inclusion criteria were microbiological contamination (bacteria or fungi) of products for parenteral administration to patients. Studies intended to simulate this were also included. The exclusion criteria were studies not published in English and all animal studies. Clinical studies involving reuse of equipment were also excluded.

The search returned a total of 8174 references and 4987 after duplicates were removed. For each of these 4987 references the title and abstract was evaluated, and after excluding those that were irrelevant to the topic of investigation (e.g. those dealing with stability studies) or did not meet the inclusion criteria (e.g. animal studies), only 33 references were left (1143). A review of the full text of each of these left 17 references for further consideration (Table 1 ) (15-20, 22, 23, 27, 29, 30, 34, 35, 38, 39, 41-43). Figure 1 shows the stages of the methodology.

The studies were divided into groups based on whether the doses were prepared individually or as part of a batch, whether the doses were made in a controlled (pharmaceutical) or an uncontrolled environment (ward or operating theatre) and whether the doses were sampled either during or after administration or if they were sampled without administration.

Doses were categorised into those that were microbiologically contaminated and those that were not. No attempt was made to identify the type and number of organisms, which were not reported in all of the references but where it was reported it mainly included skin organisms $(15,17,19,23,27,29,30,35,38,39)$.

The quality of the studies were assessed independently by the two authors using the GRADE system $(44,45)$. Disagreements were resolved by discussion. The recently published PRISMA guidelines for undertaking and presenting systematic reviews (46) were also considered. 


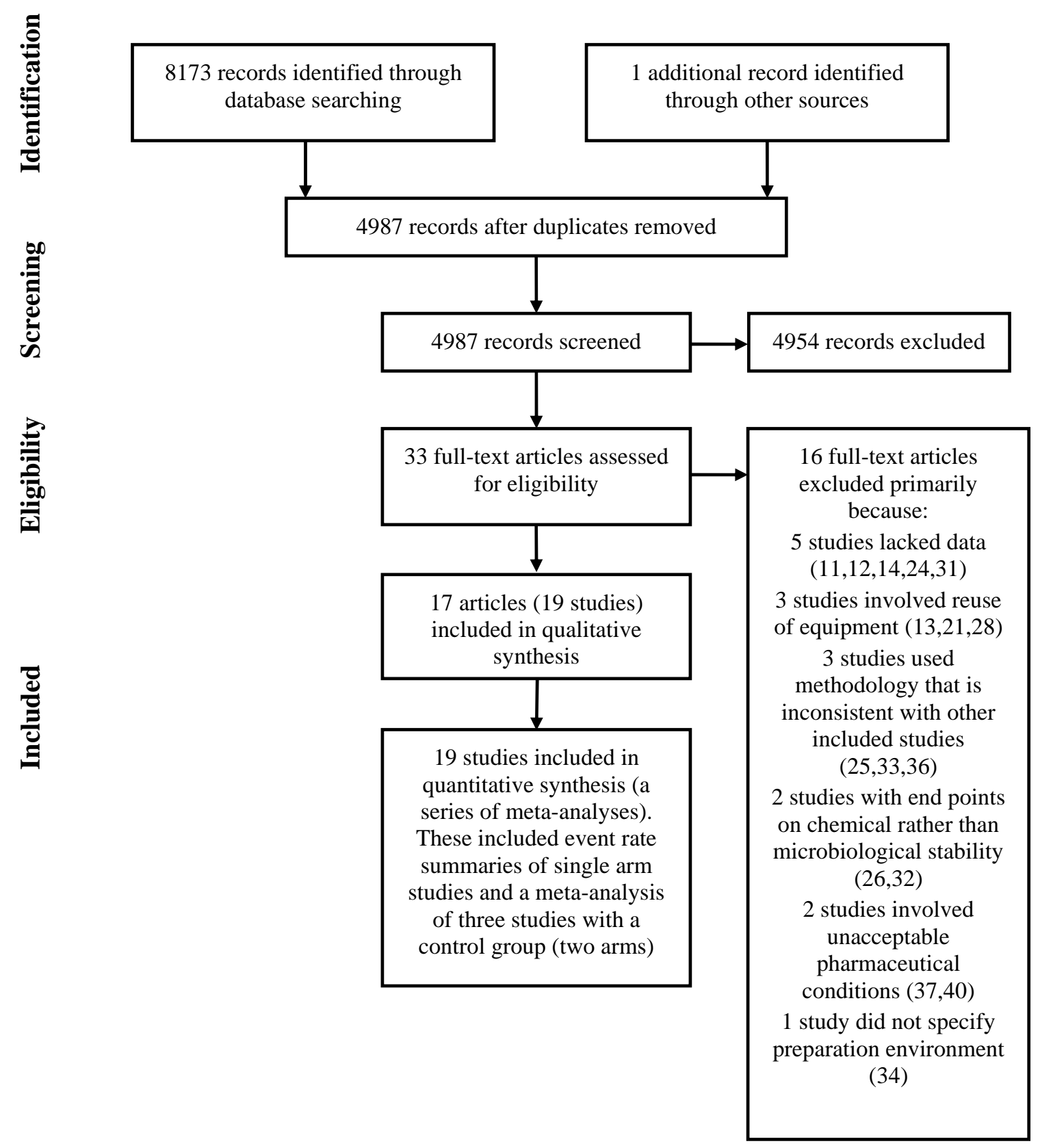

Figure 1. Summary of methodology and the systematic review process

\section{Statistics}

Point estimates and 95\% confidence intervals for contamination rates were obtained for each of the groups seperately using logit transformation. Unpaired t-tests were used in the analysis. Amalgamation of data and the meta-analysis were undertaken using a random effect model and Comprehensive Meta Analysis version 2 (Biostat, Englewood, NJ, USA). When zero rates of contamination were reported in two arms of the same study, meta-analysis was performed by using a value of 0.5 infections in each arm of the study (since mathematical difficulties arise with logarithmic (logit) transformations involving zero (log of zero $=$ minus infinity). The same was undertaken when a rate comparison in which several studies were amalgamated for a rate comparison with a single study with no contamination. The random effect model was 
chosen because of the variability of sample characteristics, interventions and comparison conditions. To further support the choice of model, heterogeneity was assessed using the $\mathrm{I}^{2}$ statistic, which is routinely displayed with fixed model analysis. A p value of $<0.05$ (two tailed) was considered to be significant.

\section{RESULTS}

\section{Quality of studies}

Both raters graded all the studies as low or very low quality. There were two disagreements within these categories which were resolved by discussion. In the end all studies were graded as

\begin{tabular}{|c|c|c|c|}
\hline Study & $\begin{array}{l}\text { Event } \\
\text { rate }\end{array}$ & $\begin{array}{l}\text { Lower } \\
\text { limit }\end{array}$ & $\begin{array}{l}\text { Upper } \\
\text { limit }\end{array}$ \\
\hline Driver et al 1998 (20) & 0.001 & 0.000 & 0.010 \\
\hline Dominik et al 1995 (19) & 0.009 & 0.005 & 0.017 \\
\hline Ernerot et al 1973 (22) & 0.010 & 0.001 & 0.138 \\
\hline Magee et al 1995 (30) & 0.041 & 0.021 & 0.080 \\
\hline Burke et al 1986 (17) & 0.284 & 0.203 & 0.383 \\
\hline Batch doses in clinical environments & 0.020 & 0.003 & 0.131 \\
\hline Yorioka et al 2006* (42) & 0.002 & 0.000 & 0.027 \\
\hline Breheney et al 1990* (16) & 0.003 & 0.000 & 0.051 \\
\hline Ernerot et al 1973* (22) & 0.023 & 0.007 & 0.069 \\
\hline Bach et al $1997^{\star}$ (15) & 0.038 & 0.029 & 0.051 \\
\hline Hernadez-Ramos et al 2000* (27) & 0.059 & 0.046 & 0.076 \\
\hline Farrington et al $1994^{\star}(23)$ & 0.070 & 0.034 & 0.140 \\
\hline Soong et al 1999* (38) & 0.083 & 0.005 & 0.622 \\
\hline D'Arcy et al $1973^{\star}(18)$ & 0.557 & 0.432 & 0.676 \\
\hline Individual doses in clinical environments & 0.050 & 0.018 & 0.131 \\
\hline Austin et al 2006 (43) & 0.000 & 0.000 & 0.008 \\
\hline Batch doses in pharmacy environments & 0.000 & 0.000 & 0.008 \\
\hline Weil et al 1988 (41) & 0.006 & 0.002 & 0.020 \\
\hline Takagi et al 1989 (39) & 0.010 & 0.003 & 0.031 \\
\hline Lawrence et al $1988^{\star}(29)$ & 0.026 & 0.011 & 0.060 \\
\hline Reiter et al 2002 (35) & 0.033 & 0.005 & 0.202 \\
\hline Reiter et al $2002^{\star}(35)$ & 0.067 & 0.017 & 0.231 \\
\hline Individual doses in pharmacy environments & 0.019 & 0.008 & 0.042 \\
\hline
\end{tabular}

low quality, mainly because they were all nonrandomised studies, except for the study of Soong et al (38) which was graded as very low quality because it was an observational study involving only 5 samples that were relevant to the present analysis.

\section{Overview of contamination rates of doses prepared in clinical and pharmaceutical environments}

The contamination rates of doses prepared in clinical environments were more variable and generally had higher contamination rates than those prepared in pharmaceutical environments (Figure 2).

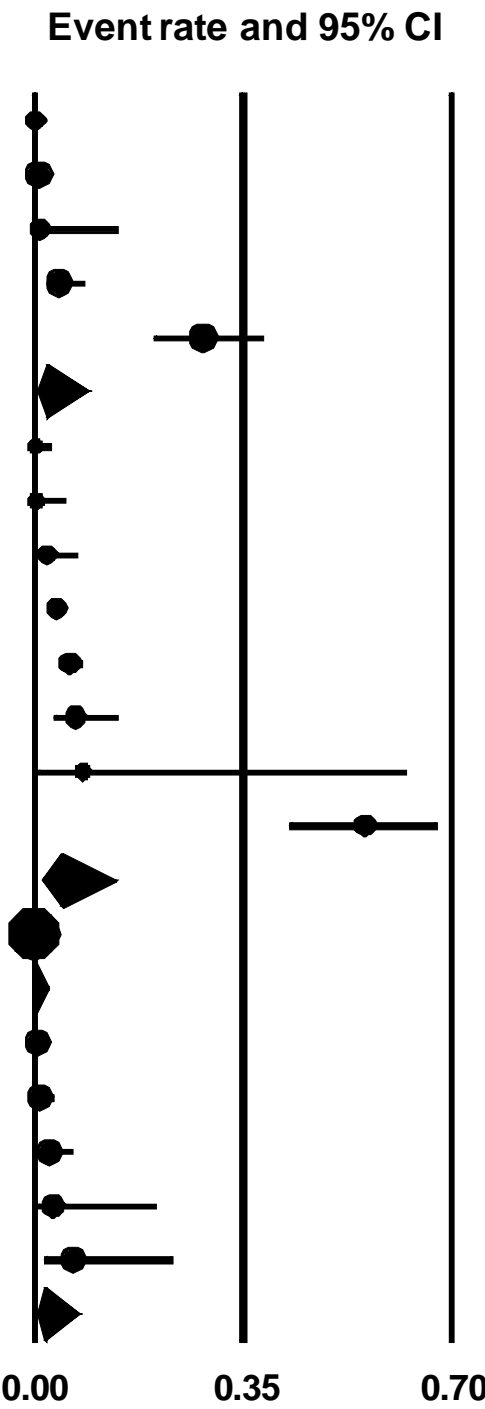

Figure 2. Contamination rates, according to clinical and pharmaceutical environments, and according to individual and batch preparation. Summary results were obtained using a random effect model. Asterisks $(*)$ indicate studies that involved sampling during or after infusion into patients, whilst no asterisks indicate sampling without administration into patients. 
In the clinical environment the between study contamination rate varied widely, from $0.1 \%$ (point estimate 0.001 ) (20) to $55.7 \%$ (0.557) (47). It also varied widely both in the subgroup of studies preparing doses as part of a batch $0.1 \%(0.001)$ (20) to $28.4 \%(0.284)$ (17) as well as individual doses $0.2 \%(0.002)$ (42) to $55.7 \%(0.557)(47)$. The point estimates (random effect model) for the group as a whole $(0.033$ (95\% CI; 0.014, 0.074)) and the two subgroups (0.050 (95\% CI, 0.018, 0.131)) for individual doses; and $(0.020$ (95\% CI; 0.003, 0.131)) for batch doses were similar. The impression of variability or heterogeneity between studies, which was established by considering study design, sample size characteristics and methodology of studies in a clinical environment, was confirmed by statistical testing $\left(\mathrm{I}^{2}=95-96 \%\right.$ in all cases; $\mathrm{p}<0.001$ ).

In a pharmaceutical environment the between study contamination rate ranged from $0.0 \%$ (point estimate 0.000 ) (43) to $6.7 \%(0.067)$ (35). It was $0.0 \%(0.000)$ in the single study of batch dose preparation (43) and less than 3.3\% $(0.033)$ in four of the remaining 5 studies (Table 1 and Figure 2). The point estimate (random effect model) for the overall contamination rate of the group was 0.014 (95\% CI 0.005, 0.037). The point estimate for the individual dose preparation was 0.019 (95\% CI $0.008,0.042)$ and for the batch dose preparation was 0.000 (95\% CI; 0.000, $0.008 ; \mathrm{I}^{2}=0.000$ ). The heterogeneity between studies was moderate $\left(\mathrm{I}^{2}=55 \%\right)$ but not significant.

The summary of the overall contamination rates shown in Figure 2, which can help examine the three individual hypotheses described below.

\section{Hypothesis 1 (preparation of doses in clinical $\mathbf{v}$ pharmaceutical environment)}

No individual studies were identified that compared contamination rates of doses (individual or batches) prepared in both clinical and pharmaceutical environments for either.

\section{Individual doses}

Ten studies involved doses that had been sampled during (27) or after $(15,16,18,22,23,29,35,38$, 42) administration. Eight of these were prepared in a clinical environment $(15,16,18,22,23,27$, 38 , 42) (total combined $\mathrm{N}=2976$ ), and two in a pharmaceutical environment $(29,35)$ (total combined $\mathrm{N}=226$ ). Contamination was greater in those doses prepared in a clinical environment rather than a pharmaceutical environment but there were large overlapping confidence intervals which would preclude significant differences (point estimates 0.050 (95\% CI $0.018,0.131)$ vs 0.035 (95\% CI 0.014, 0.085). Variability between studies undertaken in a clinical environment was judged to be greater than those in a pharmaceutical environment (supported by statistical results: $\mathrm{I}^{2}=95 \%$ in a clinical environment vs $\mathrm{I}^{2}=24 \%$ in a pharmaceutical environment).

There were no studies identified that considered the contamination rates of doses prepared individually in a clinical environment that were not administered to patients.

\section{Batch doses}

Six studies involved doses that had not been administered. Five of these were batch doses prepared in a clinical environment $(17,19,20,22$, 30) (total combined $N=2096$ ) and one study considered batch doses prepared in a pharmaceutical environment (43) $(\mathrm{N}=1002)$. Those doses prepared in a clinical environment were sampled immediately after preparation or after storage for up to 8 days. All of the doses in the pharmaceutical environment were stored for 28 days before sampling. Contamination was found to be greater in those doses prepared in a clinical than pharmaceutical environment (point estimates 0.020 (95\% CI $0.003,0.131)$ vs 0.000 (95\% CI 0.000, 0.008)), yielding highly significant differences $(\mathrm{p}<0.001)$. As can be seen from Figure 2, three of the individual dose studies were found to have significantly higher contamination rates than the batch study $(\mathrm{p}=$ $<0.001$ (17), $\mathrm{p}=0.002$ (30) and $\mathrm{p}=0.046$ (19)). The contamination rates of the other two individual dose studies were not significantly different from that of the batch study. One of these was a small study involving only 50 doses $(p=0.133)(22)$ and therefore the comparison lacked power, and the other was a larger study with no contamination ( $p=0.868)(20)$. The variability between clinical studies was confirmed by the heterogeneity statistic $\left(I^{2}=96 \%\right)$, in contrast to the single pharmaceutical study which lacks heterogeneity $\left(\mathrm{I}^{2}=0 \%\right)$.

No studies were identified that considered the contamination rates of batch doses sampled during or after administration. 


\section{Hypothesis 2 (individual $v$ batch preparation of doses)}

No individual studies were identified that compared contamination rates of individual and batch doses in a pharmaceutical environment. The only study that compared these in a clinical environment used a different methodology in each setting (22).

\section{Clinical environment}

In the clinical environment eight studies $(15,16$, 18, 22, 23, 27, 38, 42) (total combined $\mathrm{N}=2976$ ) considered rates of contamination of individual doses and 5 studies considered batch doses (17, 19, 20, 22, 30) (total combined $N=2096$ ). The individual doses had been sampled during (27) or after (15-20, 22, 23, 30, 38, 42) administration and all of the batch doses had been sampled without administration. The batch doses were stored for varying periods before sampling; without storage $(19,22)$, for up to 8 hours (30), without storage to storage for longer than 72 hours (17) or for up to 8 days (20). Contamination rates were higher for individual than batch preparations, but the 95\% confidence intervals were large and overlapping, precluding significant differences) (point estimates $0.050 \quad$ (95\% CI $0.018,0.131)$ vs 0.020 (95\% CI $0.003,0.131)$ ) (Figure 2). As expected from the characteristics of the clinical studies (Table 1) heterogeneity between them was confirmed statistically $\left(\mathrm{I}^{2}=\right.$ $95 \%$ in studies involved with batch doses and $\mathrm{I}^{2}=$ $96 \%$ in the individual dose studies).

\section{Pharmaceutical environment}

In pharmaceutical environments three studies (35, 39, 41) (total combined $\mathrm{N}=801$ ) considered rates of contamination of individual doses prepared in a pharmaceutical environment and 1 study considered batch doses (43) $(\mathrm{N}=1002)$. All 4 of these studies involved doses that had not been administered. The doses were sampled immediately after preparation (35), up to 168 hours after preparation (39), up to 15 days after preparation (41) or after 28 days storage (43). Contamination was found to be greater ( $\mathrm{p}<$ 0.001 ) in those doses prepared individually rather than as part of a batch (point estimates 0.010 (95\% CI $0.005,0.020)$ vs 0.000 (95\% CI 0.000 , 0.008)). The significance was weaker when each of the individual dose studies was compared separately to the batch study ( $\mathrm{p}=0.015$ (35); $\mathrm{p}=$ 0.049 (41) and $\mathrm{p}=0.095$ (39)) due to the loss of power associated with each individual comparison. These studies were similar in design and methodology although in one of them (35) the sample size was small. When combined the individual dose studies did not have significant statistical heterogeneity $\left(\mathrm{I}^{2}=34 \%(\mathrm{p}=0.355)\right)$.

\section{Hypothesis 3 (additions v no additions)}

No individual studies were identified that compared contamination rates of doses with and without additions in a pharmaceutical environment. Three such studies were identified in a clinical environment $(16,18,22)$ (see below).

\section{Clinical environment}

In a clinical environment three studies $(16,18$, 22) (total combined $\mathrm{N}=518$ ) considered rates of contamination of individual doses sampled after administration. Some of these doses had had drug additions made before use $(\mathrm{N}=342)$ and some had not $(\mathrm{N}=176)$. A further study was identified (34) but it was not clear if the doses were prepared in a clinical environment. Therefore, a meta-analysis was undertaken with only three studies. Although a higher overall contamination rate was found when additions rather than no additions were made, the risk ratio was not significant $\quad(1.459 \quad(95 \% \quad$ CI $\quad 0.24, \quad 8.882)$; $\mathrm{p}=0.682$ ). The differences in study characteristics were associated with moderately high statistical heterogeneity $\left(\mathrm{I}^{2}=66.45 \%, \mathrm{p}=0.055\right)$. The quality of the studies, measured using criteria in the GRADE system $(44,45)$ was considered to be low, primarily because they did not report randomisation procedures.

\section{Pharmaceutical environment}

A single study examining the effect of manipulations to make batches in a pharmaceutical environment was found to have a contamination rate of zero in a series of 1002 doses, compared to a maximum contamination expected contamination rate of 1 in a million does, according to International requirements (2).

\section{DISCUSSION}

This study demonstrates substantial variability in contamination rates in both clinical and pharmaceutical environments and the presence of frequently unacceptably high rates of contamination in these settings. Both of these issues require attention. In an attempt to reduce 
the prevalence of nosocomial infections regulatory agencies have provided a range of recommendations about preparation and administration of clinical doses. For example there is National UK guidance that any batch preparation must only be carried out in a pharmaceutical environment because products prepared in a clinical environment should be discarded after a maximum of 24 hours (48). This guidance was predominantly based on expert opinion rather than an evidence base. There is also guidance to reduce dose manipulations. However, it is unclear if such guidance is overstringent and it is unclear to what extent it is supported by an evidence base. Therefore, these issues were examined using three specific interrelated hypotheses.

\section{Hypothesis 1 (preparation of doses in a clinical $v$ pharmaceutical environment)}

The evidence that doses prepared in a pharmaceutical rather than clinical environment have a lower rate of contamination was found to be generally weak. The evidence was_stronger for batch preparations than for individual preparations. There are at least three possible reasons why better results might be expected for doses prepared in a pharmaceutical environment. First, there is greater risk of contamination in the clinical than the pharmaceutical working environment (49). Second, those working in a pharmaceutical environment are typically required to demonstrate competence at regular intervals, whereas this is less strict or does not apply in the clinical environment. Thirdly, in the case of batches, special equipment to reduce the number of manipulations is more likely to be used in the pharmaceutical than the clinical environment. The lack of stronger evidence could be due to the lack of adequately designed studies to address to address the specific issues as well as heterogeneity between studies (see section below on limitations).

\section{Hypothesis 2 (individual $v$ batch preparation of doses)}

Support for this hypothesis might have been expected because of the special equipment typically used in pharmaceutical environments to reduce the number of manipulations when preparing a batch. The data from this study support the hypothesis of reduced contamination rates in batch versus individual dose preparation in a pharmaceutical environment. No such support in a clinical environment was found, possibly because, the potentially greater risk of individual dose preparation and lack of special aseptic manipulation equipment in most clinical environments may have been offset by the increased risk of storing doses prepared as a batch. This issue about storage could not be explored further due to a lack of consistent data over comparable time periods. Another possible confounding variable is that different techniques and observers were used in the various studies.

\section{Hypothesis 3 (additions $v$ no additions in a clinical environment)}

Although the concept that additions to doses are more likely to introduce contamination than no addition has a rational basis, formal evidence is still lacking. It is noteworthy that in one of the three controlled studies that examined this hypothesis using individual doses (and another excluded study (34)), no infections were noted as a result of additions $(\mathrm{N}=150(16)$ and $\mathrm{N}=192$ (34)). However, it seems that these studies are underpowered and their overall quality considered to be poor according to the GRADE criteria (44, 45). Nevertheless they do favour limiting additions in a clinical environment whenever possible.

In the only study in which sterile doses were manipulated to prepare batches in a pharmaceutical environment no contamination was found among 1002 total doses prepared. Contamination rates of 'sterile' doses (terminally sterilised) should be no more than 1 per million doses, according to international standards (2). A sample size of 1 million per group would be required to detect 10 infections per million in the intervention group (with additions) compared to 1 per million in the control group (no additions) with $80 \%$ power and a significance of $p=0.05$.

\section{Limitations}

This systematic review has a number of limitations. First, several studies did not specifically set out to examine the hypotheses set out in this paper, and therefore comparisons involved different studies with different protocols and different observers. Second, a meta-analysis involving studies with intervention and control arms was limited by heterogeneity, in which one study reported zero infection rates in both arms and the other two much higher rates of infection. Third, the studies were reported over a period of 33 years from different countries, and this is 
likely to add to the heterogeneity. Fourth, there were variations in the method and volume of dose sampling. Therefore, one of the main findings of this systematic review is the need to undertake a series of adequately powered studies to address the gaps that have been identified and to systematically establish an evidence base to guide practice. Perhaps the most important finding is that very few individual studies offered a direct comparison of two groups (no studies to examine hypotheses 1 and 2, no studies to examine hypothesis 3 in a pharmaceutical environment and only three studies to examine hypothesis 3 in a clinical environment).

\section{Recommendations}

Although the data generally suggest advantages in preparing doses in the pharmaceutical rather than clinical environment, preferably using batch preparations and minimising manipulations, there may be additional costs in doing this. Therefore there is not only a need to strengthen the available database, but also to begin to undertake a costeffectiveness analysis, which is currently lacking. The influence that training and experience of operators performing aseptic manipulations on contamination rates of prepared doses would also be a useful addition to the current evidence base as this was not controlled in the reported studies.

\section{CONCLUSIONS}

In summary, these data suggest the presence of unacceptably frequent high rates of contamination of doses in both clinical and pharmaceutical environments, which need attention by ensuring adequate local validation of contamination rates of aseptically prepared doses. They also provide general support for the view that aseptic manipulations should whenever possible be carried out in a dedicated pharmaceutical unit with an appropriately controlled environment to minimise any risk of dose contamination. However, the evidence base is generally weak due to the limitations of the identified studies, including sample characteristics, interventions and comparison conditions. Therefore, the evidence base needs to be strengthened by designing adequately powered controlled trials involving randomisation, the use of consistent procedures wherever appropriate as well as the application of cost-effective analysis.

\section{REFERENCES}

1. Olivier LC, Kendoff D, Wolfhard U, NastKolb D, Nazif Yazici M, Esche H. Modified syringe design prevents plunger-related contamination--results of contamination and flow-rate tests. J Hosp Infect 2003;53:140-3.

2. Sharp J. Quality in the manufacture of medicines and other healthcare products. London: Pharmaceutical Press, 2000:331-360.

3. Farwell J. Aseptic dispensing for NHS patients (Farwell report). London: Department of Health, 1995.

4. Beaney A. Quality Assurance of Aseptic Preparation Services. Pharmaceutical Press, 2006:107.

5. British Standards Institution. BS EN ISO 14644-1: Cleanrooms and associated controlled environments - part 1: classification of air cleanliness. 1999.

6. Medicines Control Agency. Rules and guidance for pharmaceutical manufacturers and distributors. London: The Stationery Office, 2002:97-101.

7. Quality assurance of aseptic preparation services. In: Beaney A, ed. 3 ed. London: Pharmaceutical Press, 2001:44-46.

8. National Patient Safety Agency. Patient safety alert 20. 2007.

9. Department of Health. Breckenridge Report. London, 1976.

10. Audit Commission. A spoonful of sugar recipes for risk reduction. London, 2001.

11. Septicaemia from infusion. $\mathrm{Br}$ Med J 1969;2:462-3.

12. Contaminated infusion fluids. $\mathrm{Br}$ Med J 1972;3:190-1.

13. Contamination of multiple-dose vials due to repeat use of syringes. Cmaj 1989;140:52931.

14. Infections linked to lax handling of propofol. Am J Health Syst Pharm 1995;52:2061, 2066.

15. Bach A, Motsch J, Schmidt H, et al. In-use contamination of propofol. A clinical study. Eur J Anaesthesiol 1997;14:178-83.

16. Breheny F, McGechie D, Toohey M. Contamination of parenteral nutrition solutions not a hazard with additions made at ward level. Anaesth Intensive Care 1990;18:547-9.

17. Burke KG, Larson E, Maciorowski L, Adler DC. Evaluation of the sterility of thermodilution room-temperature injectate preparations. Crit Care Med 1986;14:503-4.

18. D'Arcy PF, Woodside W. Drug additives: a potential source of bacterial contamination of infusion fluids. Lancet ‘2:96.

19. Dominik RH, Segebade IE, Taenzer V. Risk of microbial contamination of iodinated contrast media on multiple use of largevolume bottles. Eur J Radiol 1995;19:198205. 
20. Driver RP, Jr., Snyder IS, North FP, Fife TJ. Sterility of anesthetic and resuscitative drug syringes used in the obstetric operating room. Anesth Analg 1998;86:994-7.

21. Drucker E, Alcabes PG, Marx PA. The injection century: massive unsterile injections and the emergence of human pathogens. Lancet 2001;358:1989-92.

22. Ernerot L, Thoren S, Sandell E. Studies on microbial contamination of infusion fluids arising from drug additions and administration. Acta Pharm Suec 1973;10:141-6.

23. Farrington M, McGinnes J, Matthews I, Park GR. Do infusions of midazolam and propofol pose an infection risk to critically ill patients? Br J Anaesth 1994;72:415-7.

24. Francis AE. Contaminated infusion fluids. Lancet 1972;2:285-6.

25. Hansen EW, Nielsen PL. Intrinsic and extrinsic microbial contamination of home total parenteral nutrition manufactured in evainfusion bags (the i.v. bag). J Clin Pharm Ther 1987;12:325-31.

26. Haws JL, Herman N, Clark Y, Bjoraker R, Jones D. The chemical stability and sterility of sodium thiopental after preparation. Anesth Analg 1998;86:208-13.

27. Hernandez-Ramos I, Gaitan-Meza J, GarciaGaitan E, Leon-Ramirez AR, JustinianiCedeno N, Avila-Figueroa C. Extrinsic contamination of intravenous infusates administered to hospitalized children in Mexico. Pediatr Infect Dis J 2000;19:888-90.

28. James FM, George RH, Naiem H, White GJ. Bacteriologic aspects of epidural analgesia. Anesth Analg 1976;55:187-90.

29. Lawrence J, Turner M, Gilbert P. Microbial contamination and growth in total parenteral nutrition solutions. J Clin Pharm Ther 1988;13:151-7.

30. Magee L, Godsiff L, Matthews I, Farrington M, Park GR. Anaesthetic drugs and bacterial contamination. Eur J Anaesthesiol Suppl 1995;12:41-3.

31. Martin MV. The air/water syringe: a potential source of microbial contamination. Br Dent J 1998;184:278-9.

32. Melman D, Siegel DM. Prefilled syringes: safe and effective. Dermatol Surg 1999;25:492-3.

33. Mitrano FP, Baptista RJ, Newton DW, Augustine SC. Microbial contamination potential of solutions in prefilled disposable syringes used with a syringe pump. Am J Hosp Pharm 1986;43:78-80.

34. Oie S, Kamiya A. Particulate and microbial contamination in in-use admixed parenteral nutrition solutions. Biol Pharm Bull 2005;28:2268-70.
35. Reiter PD. Sterility of intravenous fat emulsion in plastic syringes. Am J Health Syst Pharm 2002;59:1857-9.

36. Riedinger MS, Shellock FG, Shah PK, Weissfeld AS, Ellrodt AG. Sterility of prefilled thermodilution cardiac output syringes maintained at room and ice temperatures. Heart Lung 1985;14:8-11.

37. Singh RF, Corelli RL, Guglielmo BJ. Sterility of unit dose syringes of filgrastim and sargramostim. Am J Hosp Pharm 1994;51:2811-2.

38. Soong WA. Bacterial contamination of propofol in the operating theatre. Anaesth Intensive Care 1999;27:493-6.

39. Takagi J, Khalidi N, Wolk RA, Tjolsen E, de Leon R, Wesley JR. Sterility of total parenteral nutrient solutions stored at room temperature for seven days. Am J Hosp Pharm 1989;46:973-7.

40. Trissel LA, Ogundele AB, Ingram DS, Saenz CA, Gentempo JA. Using medium-fill simulation to establish a benchmark microbiological contamination rate for lowrisk-level compounding. Am J Health Syst Pharm 2003;60:1853-5.

41. Weil DC, Arnow PM. Safety of refrigerated storage of admixed parenteral fluids. J Clin Microbiol 1988;26:1787-90.

42. Yorioka K, Oie S, Oomaki M, Imamura A, Kamiya A. Particulate and microbial contamination in in-use admixed intravenous infusions. Biol Pharm Bull 2006;29:2321-3.

43. Austin P, Dixson S. Hub fluid does not increase microbiological contamination of prepared and stored syringes. Pharm J 2006;276:47-49.

44. Guyatt GH, Oxman AD, Kunz R, Vist GE, Falck-Ytter Y, Schunemann HJ. What is "quality of evidence" and why is it important to clinicians? Bmj 2008;336:995-8.

45. Guyatt GH, Oxman AD, Vist GE, et al. GRADE: an emerging consensus on rating quality of evidence and strength of recommendations. Bmj 2008;336:924-6.

46. Moher D, Liberati A, Tetzlaff J, Altman DG. Preferred Reporting Items for Systematic Reviews and Meta-Analyses: The PRISMA Statement. J Clin Epidemiol 2009.

47. D'Arcy PF, Woodside W. Drug additives: a potential source of bacterial contamination of infusion fluids. Lancet 1973;2:96.

48. British Medical Association and Royal Pharmaceutical Society of Great Britain. British National Formulary. 55 ed. Oxon: Pharmaceutical Press, 2008:822.

49. Beaney A, Goode J. A risk assessment of the ward-based preparation of parenteral medicines. Hospital Pharmacist 2003;10:3068. 
Table 1. Details of studies and reported contamination rates

\begin{tabular}{|c|c|c|c|c|c|c|c|c|}
\hline \multirow[t]{2}{*}{ Reference } & \multirow[t]{2}{*}{ Dose } & \multirow[t]{2}{*}{$\begin{array}{c}\text { Individual } \\
\text { or batch }\end{array}$} & \multirow[t]{2}{*}{$\begin{array}{c}\text { Preparation } \\
\text { environment }\end{array}$} & \multirow[t]{2}{*}{$\begin{array}{c}\text { Administration } \\
\text { to patients }\end{array}$} & \multicolumn{2}{|c|}{ Additives group } & \multicolumn{2}{|c|}{ Control group (no additives) } \\
\hline & & & & & $\begin{array}{c}\text { Total } \\
\text { number } \\
\text { of doses }\end{array}$ & $\begin{array}{c}\text { Number of } \\
\text { contaminated } \\
\text { doses }\end{array}$ & $\begin{array}{c}\text { Total } \\
\text { number of } \\
\text { doses }\end{array}$ & $\begin{array}{c}\text { Number of } \\
\text { contaminated } \\
\text { doses }\end{array}$ \\
\hline Bach et al 1997 (15) & anaesthetic agents & individual & clinical & yes & 1228 & 47 & -- & -- \\
\hline Breheny et al 1990 (16) & parenteral nutrition & individual & clinical & yes & 150 & 0 & 96 & 0 \\
\hline Burke et al 1986 (17) & $5 \%$ glucose & batch & clinical & no & 95 & 27 & -- & -- \\
\hline D’Arcy et al 1973 (18) & various & individual & clinical & yes & 61 & 34 & 40 & 5 \\
\hline Dominik et al 1995 (19) & contrast media & batch & clinical & no & 1000 & 9 & -- & -- \\
\hline Driver et al 1998 (20) & various for obstetric theatre use & batch & clinical & no & 756 & 0 & -- & -- \\
\hline Ernerot et al $1973^{\mathrm{a}}(22)$ & various & batch & clinical & no & 50 & 0 & -- & -- \\
\hline Ernerot et al $1973^{\mathrm{a}}(22)$ & various & individual & clinical & yes & 131 & 3 & 40 & 2 \\
\hline Farrington et al 1994 (23) & midazolam or propofol & individual & clinical & yes & 100 & 7 & -- & -- \\
\hline Hernandez-Ramos et al 2000 (27) & various & individual & clinical & yes & 1011 & 60 & -- & -- \\
\hline Lawrence et al 1988 (29) & parenteral nutrition & individual & pharmaceutical & yes & 196 & 5 & -- & -- \\
\hline Magee et al 1995 (30) & $\begin{array}{c}\text { anaesthetics, } 0.9 \% \mathrm{NaCl} \text { and } \\
\text { growth medium }\end{array}$ & batch & clinical & no & 195 & 8 & -- & -- \\
\hline Reiter et al $2002^{\mathrm{b}}$ (35) & 20\% lipid & individual & pharmaceutical & yes & 30 & 2 & -- & -- \\
\hline Reiter et al $2002^{\mathrm{b}}$ (35) & $20 \%$ lipid & individual & pharmaceutical & no & 30 & 1 & -- & -- \\
\hline Soong et al 1999 (38) & propofol & individual & clinical & yes & 5 & 0 & -- & -- \\
\hline Takagi et al 1989 (39) & parenteral nutrition & individual & pharmaceutical & no & 300 & 3 & -- & -- \\
\hline Weil et al 1988 (41) & various & individual & pharmaceutical & no & 471 & 3 & -- & -- \\
\hline Yorioka et al 2006 (42) & electrolytes and dobutamine & individual & clinical & yes & 290 & 0 & -- & -- \\
\hline Austin et al 2006 (43) & growth medium & batch & pharmaceutical & no & 1002 & 0 & -- & -- \\
\hline
\end{tabular}

${ }^{\mathrm{a}}$ and ${ }^{\mathrm{b}}$ Different issues addressed in the same publication 